\title{
DESIGN OF RELIABLE PRODUCTION ROUTE SYSTEM
}

\author{
KARAULOVA, T[atyana]; PRIBYTKOVA, M[arina]; SAHNO, J[evgeni] \& SHEVTSHENKO, E[duard]
}

\begin{abstract}
Today, in order to survive in fast-growing and technologically driven world, organizations should be able to store their data into Data Warehouse, manage it and share within enterprise and partners. This paper is intended for the companies interested in the practical experience of the Information Management Systems. The presented architecture of production route design describes the process of production data collection, definition, integration and extraction for specified project. The introduced reliability analysis module enables to assess and apply technological route for new orders, to minimize the production time and cost.
\end{abstract}

Keywords: ERP, data warehouse (DW), failure modes and effects analysis (FMEA), self organizing map (SOM)

\section{INTRODUCTION}

The current research is focused on design of reliable production route system intended for manufacturing enterprises that produce metal construction products. This module will be used for improvement of profitability and sustainability of manufacturing processes in industrial enterprises and collaborative networks. The first goal of this paper is to create module that could collect and save technological knowledge into DW and ability in the future extract them when it needed. The second goal is to evaluate Reliability analysis module for production process to pinpoint potential areas for improvement, thereby identifying the most likely failures and then selecting the appropriate actions, it will alleviate the consequences of those failures. This research will help to develop the new vision of future manufacturing.

\section{PROBLEMS AND BACKGROUND}

ERP system is a comprehensive transaction management system that integrates different ways for information processing that keeps data in a single database. The limitations of current ERP systems are known today in providing effective Supply Chain Management (SCM) support: their insufficient extended enterprise functionality in crossing organizational boundaries; their inflexibility to ever-changing supply chain needs; their lack of functionality beyond managing transactions, and their closed and non-modular system architecture (Caiazzo et al., 1997). To solve those limitations of ERP systems the integration with DW systems are widely used as centralized source of information available for the partners by request. The DW input data can be provided from any source of information, and due to this property it is suitable management system of partner enterprises. It improves the productivity of corporate decision makers through consolidation, conversion, transformation, and integration of operational data, and provides a consistent view of an enterprise (Berson, A., Smith, S.J., 1997).

\section{ARCHITECTURE OF PRODUCTION ROUTE}

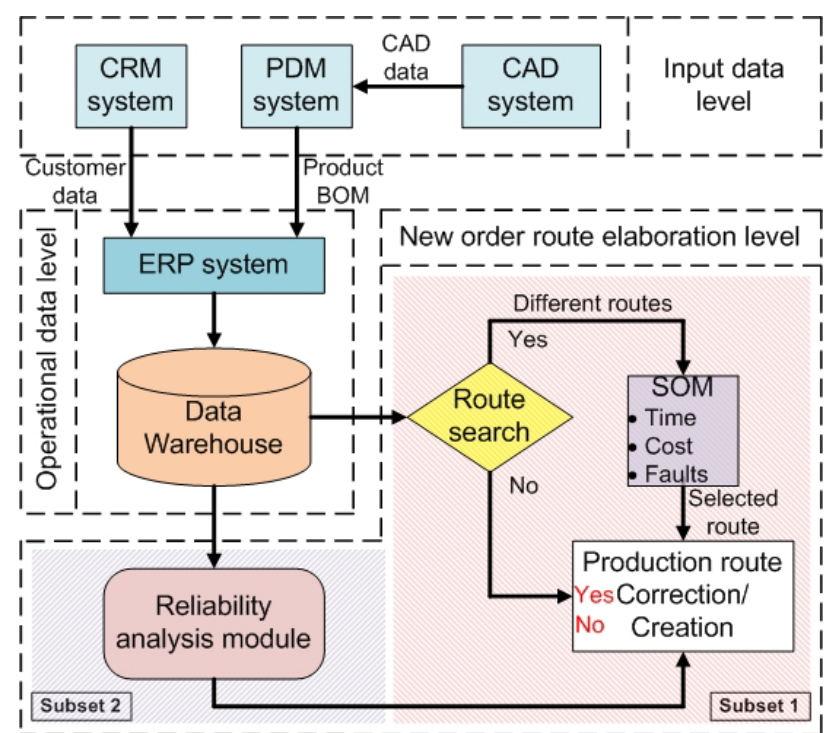

Fig. $\overline{1} . \bar{A}$ Architecture of production route system

The architecture of production route system consist from the following levels: Input data level, Operational data level and New order route elaboration level as presented in Figure 1. When the new product design process is started the comprehensive search engine could be used in order to discover all possible production routes from historical data, based on the product parameters. After the total list of possible production routes is discovered the Kohonen SOM are constructed based on such criteria as: production route time, total cost and percentage of faults for every Work Station (WS) used in operations is presented to decision maker for final selection of the best alternatives. The percentage of WS faults is calculated by reliability analysis module based on historical data. For this purpose the number of products with defects produced by every WS is divided by the total number of product produced.

\subsection{Input data level}

The CAD data is converged to PDM system where the product $\mathrm{BOM}$ is prepared. The marketing, sales orders, customer contact and contracts data is stored to CRM system. The selected input level data is replicated to Operational data level. (Zahharov et al., 2009)

\subsection{Operational data level}

The operational data of enterprise is managed by the integrated cross-functional ERP system. The integration is made through a data base shared by all functions and data processing applications in the company. The operational data required for analysis and reporting is replicated to DW.

\subsection{New order route elaboration level}

This level is consists of two subsets that applied for relevant production route search for the product (assembly) 
with its constituent parts - BOM that was transferred from Input data level to ERP system. The first subset demonstrates item data definition like assembly/part type, its name or material profile, dimensions and material mark. All these item data linked with production route stored in DW. After the item is defined, the system search engine finds similar production route code. There are could be a lot of production routes found in $\mathrm{DW}$, in order to sort the most successful, the SOM that is constructed to show the discovered list of possible routes based on the following parameters: time, cost and percentage of faults and which simplifies the production route selection process, propose us some satisfactory routes. As the result, the decision maker defines the most suitable one. If the similar production route is selected it is copied and corrected as required for particular product, if no production route is discovered the new production route is created. The creation/correction of production route is supported by Reliability analysis module. The goal of this module is elaboration of the reliability of a production processes to pinpoint potential areas for reliability improvements. In reality all failures cannot be eliminated by design changes, so another goal of reliability engineering is to identify the most likely failures and then to select the appropriate actions to mitigate the effects of those failures.

\section{RELIABILITY ANALYSIS MODULE}

The second subset of New order elaboration level focused on the Reliability analysis module structure development for manufacturing enterprises. It is used for improvement of profitability and sustainability of manufacturing processes in industrial enterprises and collaborative networks. The first step is elaboration of DW structure for ERP data archiving and analysing. DW structure must be universal for different ERP, which requires adaptation to enterprises system.

The main function of Reliability analysis module is determination of the failures which may arise in operation and give the recommendation for elimination. The system must calculate probability of reliability increasing in case of elimination of every potential failure of the process. Data for analyse will be taken from production route in ERP system. After the required level of reliability is achieved the production route is imported to ERP system. Reliability analysis module main functions and data flows are shown in Figure 2.

When the suitable production route is discovered the process of route modification for particular order is started in Reliability analysis module. When the new operation is selected the percentage of faults for used WS is shown. If the percentage of faults is low the next operation is added to production route. If the percentage of faults is high the corrective actions should be added.

\subsection{FMEA and faults group definition}

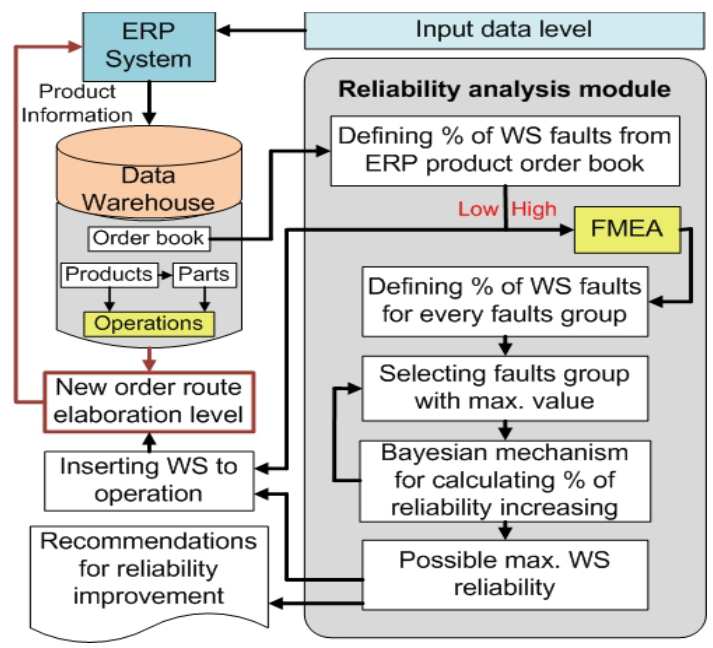

Fig. 2. The reliability analysis module structure
FMEA is a preventive technology for reliability design and analysis by applying structured systematic procedures and methods to locate the potential failure modes of products at an early stage. Causes of failures and impacts of such failures upon the subsystem and the system above are examined for adoption of proper preventive measures and improvement proposals. It is usually performed in the beginning of a product life cycle to increase the reliability of products or process and to reduce the costs for follow-up corrective and improvement actions (Sharon, 1998).

In order to discover the critical factors that influence the reliability of particular production route and to increase the level of WS reliability the data received from ERP system is combined with the FMEA data. The main faults groups that influence the WS reliability are: equipment faults, technological faults, labour fault and subcontractor (supplier) faults.

The FMEA data will enable to calculate the Risk Priority Number (RPN) for every fault occurred. The multiplied risk factor refers to Severity (S), the outcome of a failure, Occurrence (O) and Detection (D), the chance of a failure is not detected by customers. Based on collected statistical data it is possible to assess the influence of every fault type and to select the appropriate corrective actions (Pribytkova et al., 2010).

\subsection{Bayesian mechanism for reliability calculation}

Reliability analysis module supports the corrective action selection process. The Bayesian mechanism enables to select the appropriate recommendation for WS reliability improvement without the significant increase of production cost. The documented recommendations for reliability improvement are available from Reliability analysis module for corrective actions planning process.

\section{CONCLUSION}

This reliable production route system enables transparent data flow from Input data level to Operational data level and than to New order route elaboration level where occurs easy and fast search of production route data and than combination with the FMEA that provides reliable production route. This solution reuse the historical data for new production routes elaboration, increase the reliability of new production routes, and creates the recommendations for future reliability improvements.

\section{ACKNOWLEDGEMENTS}

Hereby we would like to thank the Estonian Ministry of Education and Research for targeted financing scheme SF0140113Bs08 and Doctoral school of energy and geotechnology II that enabled us to carry out this work.

\section{REFERENCES}

Berson, A.; Smith, S. J. (1997). Data Warehousing, Data Mining \& OLAP, McGraw-Hill Inc, 0070062722, USA

Caiazzo, F.; Pasquino, R. \& Sergi, V. (1997). Two-dimensional objects recognition and fuzzy classification approach, Proceedings of III A.I.T.E.M. Conf., Fisciano (SA), pp. 277-286

Pribytkova, M., Polyanchikov, I. \& Karaulova, T. (2010). Influence of variability on a reliable production process, Annals of DAAAM for 2009 \& Proceedings of the 21th International DAAAM Symposium, Zadar, pp. 329-330

Sharon, K. J. (1998). Combing QFD and FMEA to optimize performance, ASQC Quality Congress, (Vol. 52), (564-575)

Zahharov, R., Shevtshenko, E., Karaulova, T.(2009) Integrated CAD/ERP Framework for Modular Construction Industrialization Through Lean Manufacturing Concepts. Annals of DAAAM for 2009 \&Proceedings of the 20th International DAAAM Symposium. Vienna, Austria, (Vol.20) pp. (591-592) 